Canadian Journal of Higher Education

Revue canadienne d'enseignement supérieur

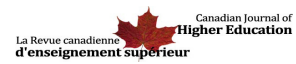

\title{
What's the protocol? Canadian university research ethics boards and variations in implementing Tri-Council policy
}

\author{
Grace Karram Stephenson, Glen A. Jones, Emmanuelle Fick, Olivier \\ Bégin-Caouette, Aamir Taiyeb and Amy Metcalfe
}

Volume 50, Number 1, 2020

URI: https://id.erudit.org/iderudit/1069652ar

DOI: https://doi.org/10.7202/1069652ar

See table of contents

Publisher(s)

Canadian Society for the Study of Higher Education

ISSN

2293-6602 (digital)

Explore this journal

Cite this article

Karram Stephenson, G., Jones, G., Fick, E., Bégin-Caouette, O., Taiyeb, A. \& Metcalfe, A. (2020). What's the protocol? Canadian university research ethics boards and variations in implementing Tri-Council policy. Canadian Journal of Higher Education / Revue canadienne d'enseignement supérieur, 50(1), 68-81. https://doi.org/10.7202/1069652ar
Article abstract

This article is concerned with the differences in REB policy and application processes across Canada as they impact multi-jurisdictional, higher education research projects that collect data at universities themselves. Despite the guiding principles of the Tri-Council Policy Statement 2 (TCPS2) there is significant variation among the practices of Research Ethics Boards (REBs) at Canada's universities, particularly when they respond to requests from researchers outside their own institution. The data for this paper were gathered through a review of research ethics applications at 69 universities across Canada. The findings suggest REBs use a range of different application systems and require different revisions and types of oversight for researchers who are not employed at their institution. This paper recommends further harmonization between REBs across the country and national-level dialogue on TCPS2 interpretations.
Copyright (c) Grace Karram Stephenson, Glen A. Jones, Emmanuelle Fick, Olivier Bégin-Caouette, Aamir Taiyeb, Amy Metcalfe, 2020
This document is protected by copyright law. Use of the services of Érudit (including reproduction) is subject to its terms and conditions, which can be viewed online.

https://apropos.erudit.org/en/users/policy-on-use/ 


\title{
WHAT'S THE PROTOCOL? CANADIAN UNIVERSITY RESEARCH ETHICS BOARDS AND VARIATIONS IN IMPLEMENTING TRI-COUNCIL POLICY
}

\author{
GRACE KARRAM STEPHENSON \\ OISE, UNIVERSITY OF TORONTO \\ GLEN A. JONES
OISE, UNIVERSITY OF TORONTO \\ EMMANUELLEFICK \\ OISE, UNIVERSITY OF TORONTO \\ OLIVIER BÉGIN-CAOUETTE \\ UNIVERSITÉ DE MONTRÉAL \\ AAMIR TAIYEB
OISE, UNIVERSITY OF TORONTO \\ AMY METCALFE
UNIVERSITY OF BRITISH COLUMBIA
}

\begin{abstract}
This article is concerned with the differences in REB policy and application processes across Canada as they impact multi-jurisdictional, higher education research projects that collect data at universities themselves. Despite the guiding principles of the Tri-Council Policy Statement 2 (TCPS2) there is significant variation among the practices of Research Ethics Boards (REBs) at Canada's universities, particularly when they respond to requests from researchers outside their own institution. The data for this paper were gathered through a review of research ethics applications at 69 universities across Canada. The findings suggest REBs use a range of different application systems and require different revisions and types of oversight for researchers who are not employed at their institution. This paper recommends further harmonization between REBs across the country and national-level dialogue on TCPS2 interpretations.

Keywords: research ethics, university ethics, higher education, social science research, harmonization
\end{abstract}

\section{Résumé}

Cet article étudie les différences entre politiques institutionnelles en matière d'éthique à la recherche et les procédures d'évaluation qui encadrent les travaux des comités d'éthique à la recherche (CER), en particulier lorsqu'il s'agit de projets de recherche en sciences sociales menés dans des universités de différentes provinces. Malgré l'adhésion générale aux principes directeurs du deuxième Énoncé de politique des trois Conseils (EPTC2), les pratiques des CER diffèrent, en particulier lorsqu'il s'agit de répondre à des chercheurs issus d'autres universités. Cette étude s'appuie sur une analyse des demandes d'évaluation soumises aux CER de 69 universités canadiennes. Les résultats suggèrent que les CER utilisent différents mécanismes de dépôt, exigent différents niveaux de révision et supervisent différemment les études dirigées par des chercheurs d'autres établissements. Cet article recommande une plus grande harmonisation des procédures des CER canadiens.

Mots-clés : d'éthique à la recherche, harmonisation, l'enseignement supérieur, science sociale

\section{Introduction}

"Whose policies ought to be followed? What is the moral force of one policy against another? When studies are pursued across multiple jurisdictions, how should conflicting moral guidance be reconciled?"

(Kimmelman, McDonald, \& Avard, 2011, p. 7)

Academic researchers across Canada can attest to the vigilant precision of research ethics boards (REBs) in scrutinizing the safety of research proposals involving human participants. Many institutions develop support systems and offer workshops to ensure professors and students are adequately trained to file applications with their REB. However, despite the comprehensiveness of REB systems within institutions, there is significant variation among institutions. For example, some institutions require researchers to submit a full literature review while others do not. Likewise, some institutions 
ensure their researchers complete the Tri-Council's online course on ethical research while others do not. This article examines the practices of university REBs across Canada and considers how federal-level policy is implemented differently at different institutions. Variations in REB requirements have significant implications for national social science research on higher education and raise questions about who is responsible for research design and dissemination.

Since the first edition of the Tri-Council Policy Statement (TCPS) was published in 1998, there has been increasing synchrony of research ethics standards across Canada. The Tri-Council, comprised of the Canadian Institutes of Health Research (CIHR), the Natural Sciences and Engineering Research Council (NSERC), and the Social Sciences and Humanities Research Council (SSHRC), requires institutions to be compliant with TCPS guidelines in order to receive federal grants and safeguard quality research. In the university sector, all public universities have a Research Ethics Board (REB), often a division of the office of the Vice President Academic or Research, which is charged with ensuring researchers appropriately adhere to the TCPS guidelines as they design, conduct and conclude their research. It is in this translation from TCPS guidelines to institutional policy that a noticeable disjuncture occurs. The TCPS documents set out standardized principles but there are significant differences among university REBs' practices as they enforce these principles in the evaluation of nascent research proposals.

This disjuncture was particularly noticeable for our higher education research team throughout the 20172018 academic year as we applied for permission from REBs across Canada to disseminate a survey and conduct interviews with professors at provincially funded universities. Although our home institution had approved our ethics application, we thought it prudent to seek REB consent from the 69 institutions at which we planned to recruit participants. This process of applying for consent to conduct our study took place over a 10-month period and revealed noticeable differences in what university REBs in Canada require from researchers outside their institution, or external researchers, in order to conduct their study ethically. Some institutions required a more detailed explanation of the research proposal than our home institution had done originally while others required nothing at all. These discrepancies piqued our interest in the standardization or harmonization of ethics application processes in Canada, whereby efforts are made to establish the same practices across institutions. We developed a side-study to our survey by observing the variations in ethics application protocol as we compared the responses, requirements and revisions at participating institutions.

It is the side-study, analyzing differences in REB application processes, that is the focus of this paper, specifically the translation of TCPS guidelines into policy at Canadian universities. Discrepancies between applications are particularly noticeable for researchers of higher education. As higher education scholars, our sites of research are frequently universities, and our research participants are the faculty, students and staff who form the academic body. A necessary step in accessing this academic body is ethical approval from the REB at the sample institution. Data collection that involves participant recruitment at more than one university often requires separate REB approval from each institution. In these cases, the subtle distinctions among REB policies require researchers to submit and revise multiple applications to proceed with their research. While the complexity and diversity of these requirements are inconvenient and produce time delays, they also raise questions that go beyond any individual project, including issues around survey ownership, the "location" of online surveys, the impact of technology on REB work, and the overemphasis on consent, rather than data collection, when revising protocols.

It is important to state at the outset of this article that the study, from which the experiences described below were drawn, was a low-risk, social science study that required REB permission at multiple universities in Canada, institutions which were themselves the research sites. Studies of this nature are a small minority among the types of studies REBs are regularly asked to review. However, in the last 15 issues of the Canadian Journal of Higher Education, 21 studies matched this profile, having collected data at more than one university, and these studies likely conducted multi-jurisdictional ethics reviews. The advancement of harmonization across Canadian REBs would certainly be of direct benefit to higher education researchers. This paper advocates for more harmonization of REB practices in the social sciences. 


\section{The Development of Ethics Standards in Canada}

The codification of ethics standards in the original Tri-Council Policy Statement (TCPS) of 1998 was an important step in establishing collaboration across the different research councils (TCPS2, 2018) and requiring compliance from university REBs. Prior to 1998 , research involving human subjects was discussed in the policy documents of the Medical Research Council Guidelines on Research Involving Human Subjects (1987) and the Social Sciences and Humanities Research Council Guidelines (1979), an offshoot of the Canada Council documents of 1976 . However, these main documents were underused by researchers and REBs since their guidelines had little capacity to require compliance. Furthermore, until the TCPS, the Natural Sciences and Engineering Research Council (NSERC) had no guiding policy documents. While REBs were still very active in regulating research at their respective institutions, this was largely an autonomous, unregulated process. McDonald (2009) points to four factors that made this deficit very acute by the early 1990s and called for the creation of a unified policy for Canadian research ethics: technological advances in research and research storage (i.e. computers, internet); the voices of marginalized participants who raised new ethical questions about research (i.e. HIV, women's health); the global adoption of the USA's Common Rule, which Canadian researchers were increasingly required to comply with to receive $\mathrm{NIH}$ funding; and the domestic expansion of Canadian medical research to consider health research more broadly, later resulting in the emergence of CIHR.

Led by these pressures in the medical sciences, the Council Presidents created the Tri-Council Working Group on Ethics (TCWG) in 1994 which was tasked with reviewing current policy and suggesting future directions for national ethics standards. By 1996, TCWG had written the Code of Ethical Conduct for Research Involving Humans, or "The Code," which was taken across Canada for consultation and review at different universities (Palys, 1996). Critics suggested that this process revealed the deep divides between disciplinary understandings of ethical standards (Grover, 2004; van den Hoonaard, 2011; Tilley, 2008) and left social scientists with a "substantially altered document" that did not reflect their input (McDonald, 2009, p. 17). The final docu- ment, the Tri-Council Policy Statement: Ethical Conduct for Research Involving Humans (TCPS) was formally adopted in 1998, with updates encoded in 2000, 2002, and 2005 (Davies, 2008). The TCPS linked REB practice to a common standard by requiring institutions to comply with its articles in order to receive their Tri-Council funding. In 2008, 2010 and 2018 new drafts, entitled TCPS2, were developed that updated several areas, revised terminology and expanded the protection of research participants with a particular focus on Indigenous communities. Currently, the TCPS2 is an online document that is updated and revised when new ethical contingencies emerge.

\section{The Social Science Critique of REB Practices}

Despite the transparency and dynamic evolution of the TCPS document, it garnered significant critique during the early 2000s in the Canadian literature on research ethics, particularly from scholars in social science fields and qualitative researchers. During the consultation phase of TCWG, those in the social sciences argued the new policy standards constructed a particular conception of ethical research that was heavily dictated by medical research, specifically around issues of harm and consent (Grover, 2004). Further criticism suggested a medical bias in ethics review processes had implications for what type of research is sanctioned, what methods are privileged, and what types of questions guide research (Chaiton, Paquet, \& Wilson 2000; Porter, 2008; Tilley, 2008). Even those who helped craft the TCPS documents described "how pervasive the power of medically oriented research ethics codes is in taking ownership away from the social sciences of their own ethical conceptions of research" (van den Hoonaard, 2018, p. 2). Likewise, Porter (2008) argues that the TCPS standards have been "imposed on the social science and humanities (SSH) research community with little sensitivity to the distinctive problems of SSH research" (p. 495). To tackle policy discrepancies, social scientists in New Brunswick hosted the Ethics Rupture Summit with the intent of re-framing REB policies to account for social science methodological approaches.

Scholars contend the challenges they encounter within REB policy are not esoteric or merely inconvenient. Rather, when REB policies are not contextualized 
to the field of research they govern, they might produce unintended changes in researcher behaviour and in the research itself. For example, standard data collection methods in qualitative social sciences, such as participant observation, may become too difficult to carry out (how does one get "permission" from everyone in large groups and even passers-by?). Another example might be requirements to destroy data by a certain date, in which case a longitudinal study might become impossible (McDonald, 2009).

The opposite critique of ethics reviews comes from Grover (2004) who suggests ethics reviews are too researcher-focused. She argues the dominant principle of academic freedom underpins REB policies and was given priority in TCPS documents. She suggests that ethics policies should operate within a human rights framework that protects participants, rather than an academic freedom framework which protects the researcher. Both views are reflected in the international literature which suggests REBs face the challenging task of protecting both researchers and participants from the unexpected impacts of research (Morrow \& Richards, 1996; Powell \& Smith, 2006). The international literature confirms tensions in REB practices both outside and inside the social sciences, and points to an epistemological difference between fields of research-a conflict that exists among social sciences scholars themselves (Tierney \& Blumberg Corwin, 2007). As inter-disciplinary social scientists, higher education scholars are often caught within these epistemological debates over what types of research should be conducted and how REBs can authentically guide that process. Moreover, higher education researchers occasionally find themselves in a position where their research findings critique the very institutions that uphold their academic freedom. Given this unique positioning, higher education scholars would benefit from collaboration with REBs that is based on a deeper mutual understanding.

A separate critique of the ethical review processes at Canada's universities relates to questions of academic freedom and surveillance. Several studies posit the notion of ethics creep, the phenomenon of REBs expanding their administrative reach and increasing their control of emerging research (Guta, Nixon, \& Wilson, 2013; Haggerty, 2004; Tilley, 2008). Guta, Nixon, and Wilson (2013) position the "expanding reach of ethics review within a neoliberal apparatus" and link it to broader "changes to academic, institutional, and com- munity cultures" (p. 303). Haggerty (2004) compares the stringency of social science ethics with the flexibility of journalism ethics, pointing to the dramatic expansion or creep of the regulatory systems in the former. He argues that social scientists are severely limited by over-regulations throughout the ethics review process in contrast to their colleagues in journalistic fields.

The above debates over the TCPS guidelines seem to suggest two options when considering the challenges social scientists encounter in obtaining ethics approval: either social scientists are working within a system that is not designed for them or they are experiencing the effects of ethics creep where increased risk management is limiting methodological innovation. Each of these perspectives captures only one angle of the challenges social science researchers face in this context. Our study extends these perspectives by using a post-hoc analysis to reflect on our recent lived experience conducting research across Canada. We identify a third challenge specific to researchers applying for ethics approval at a university that is not their own. To explore this angle, we ask the following questions:

1. What are the different application processes for researchers who apply for ethics approval at a university that is not their own?

2. What type of revisions are researchers required to implement?

3. What might the areas of divergence and convergence suggest about the construction of ethical research at different institutions?

\section{Methods}

\section{Conducting a Review of Ethics Applications}

The importance of the above questions was highlighted in the ethics application phase of a recent multi-jurisdictional study that collected data from university faculty via a large online survey. The study was conducted by the Canadian chapter of the Academic Profession in the Knowledge Society (APIKS) project, an international collaboration of 32 countries surveying faculty for their perceptions of academic work. The Canadian team was tasked with selecting the Canadian sample of faculty and distributing the bilingual (English and French) survey, 
followed by interviews at select institutions. For feasibility, 69 institutions across Canada's 10 provinces were invited to participate in the APIKS survey. In order to increase response rates, the proposed study asked the senior administration at the university to send out the email invitation and survey link to their faculty list through their own email system. Over a period of 10 months (June 2017-April 2018), the research team sought ethical permission to conduct this low-risk social science study at the 69 sample institutions.

At the sample universities, the first point of institutional contact was an email letter sent to the relevant ethics officer at the REB at each university. Attached to the email was the full, approved ethics application from University of Toronto and the approval certificate. The email message requested that the receiving REB accept these documents in lieu of their own application process, and where this was not possible, to specify the process of review required by the institution for an externally approved research project. Institutional REB responses varied significantly from those that accepted the University of Toronto documents in lieu of their own, to those who required a full review.

Throughout this process, a detailed Excel spreadsheet was created to document the correspondence, ethics requirements, application submission and revision requests from each institution. These entries were later analyzed for trends and variations among institutions in order to better understand REB approaches across Canada. These findings were presented at the annual conference of the Canadian Association for Research Ethics Boards (CAREB) in April 2018, where the research team received important feedback to further the analysis. The following findings draw on publicly available information and institutional names have been removed to anonymize the data.

\section{Limitations}

This study is not a comprehensive examination of all ethics practices across Canadian REBs. Rather, the findings draw on the experiences of one research team, comprised of members from three universities in three provinces and proposing a low-risk study. The research questions above were formed post-hoc as a reflective analysis of our lived experience with pan-Canadian ethics reviews. Furthermore, at institutions with REB sub-committees responsible for medical or social sci- ences, our research team only interacted with the social sciences committees. It is also important to note that the numbers associated with each response below may not be reflected in another research team's experiences since there was evidence that individual ethics officers or REB directors may have made contextual choices to expedite our study due to its low-risk nature. Although limitations exist regarding the applicability of these findings, there is an international body of research on ethics policies that is steadily growing-much of which uses document analysis as the main approach to data collection. Our findings contribute to broader discussions on the production of ethical research (Christensen \& Prout, 2002; Powell \& Smith, 2006).

\section{Findings from a Review of REB Practices}

\section{Variation in Reception of Externally Approved Applications}

Across the 69 REBs that were approached for this study, there are significant differences in how each receives externally approved research. In the provinces of Alberta and British Columbia, recently adopted harmonization policies require institutions to accept research protocols that have been approved at other universities in their province. A researcher who wishes to collect data at another institution in the same province first approaches their own university's REB. Once they obtain an approval certificate, an officer at their own institution's REB contacts the other university's REB to inform them of the approval. Under this process, the researcher only requires the approval certificate from their own institution to proceed with their research. Furthermore, the researcher is not required to contact the second institution's REB, saving time and effort for both the researcher and the ethics officers at the second institution. Unfortunately, the location of our research team in a different province added some complexity to this process since our own REB was not informed of these rules nor connected to the harmonization systems of Alberta and British Columbia. Rather, we encountered four main responses when we sent our initial invitation email to each REB with the attached protocol and approval certificate. 
Table 1. Comparing the responses of REBs to externally approved research

\begin{tabular}{|l|c|c|}
\hline Response & Number of Institutions & Percentage \\
\hline $\begin{array}{l}\text { Do not consider external researchers or on-line } \\
\text { research to be in their mandate }\end{array}$ & 2 & 3 \\
\hline $\begin{array}{l}\text { Accept externally approved application in lieu of } \\
\text { local application }\end{array}$ & 22 & 32 \\
\hline Short form for externally approved research & 19 & 27 \\
\hline Full Review & 26 & 38 \\
\hline TOTAL & 69 & 100 \\
\hline
\end{tabular}

The first response, as Table 1 indicates, was encountered at two institutions and stated that external researchers are ineligible to apply for ethics approval at the institution, since the institutions view external researchers or online research as outside their mandate. The text from University A's online information form is very clear: "If you are a non-[University $A]$ researcher you are ineligible to submit a [University A] research ethics application to the [University A] Research Ethics Board..." These institutions viewed our work as outside their jurisdiction and accepted our home institution's certificate.

For our study, this response allowed us to immediately begin the recruitment and data-collection portion of our research, since those institutions were allowing us to operate on the approval certificate of our home institution. Although this was not a common response from REBs, it provides an example of REBs limiting their scope to the activities of their own professors, and accepting the authority or ability of other REBs. This process also suggests scope-of-practice boundaries, where REBs have delineated clearly the research for which they are responsible. Establishing the scope-of-practice at an REB may offer one way to limit ethics creep, since REBs are not taking undue action on each application that comes their way.

The second response, from 22 institutions (32\%), was to accept the University of Toronto ethics protocol and approval certificate, delegating it for review by the REB chair or an ethics officer. At these institutions, the process of gaining ethical permission was often quite quick, allowing the research team to begin data collection within two or three weeks. Although these universities did not require their own paperwork to accompany the project, the University of Toronto documents remained on file at the institution so a record of the research was permanently available in the files of the REB.

The researcher must submit to the [University $B$ ] REB ethics protocol approved by his/her institution and the certificate of approval from the said institution when the collaboration of individuals affiliated with [University $B$ ] is required for the project. (University B, Ethics Protocol Form)

The third type of response was from 19 institutions (27\%) that required a cover letter or short form to accompany the approved protocol and certificate from the University of Toronto. In some cases, the institution also asked for the revision materials associated with the original review. When the necessary documents were provided, they were then sent for delegated or expedited review. Below is an example of this type of response:

If the project for which you require [University C] REB approval has already been reviewed and approved by another TCPS-compliant institution, rather than submit a new REB application on [University C] forms, Research Ethics tries to make the process of multi-jurisdictional review easier for researchers by accepting submissions as follows:

1. The first page of the [University C] research ethics application form (section 1, with the administrative information complete)

2. The full application to the other TCPS-compliant institution

3. The review material from the other institution's REB

4. The approval letter from the other institution's REB

(University C, Ethics Protocol Form) 
The final type of response, at 26 universities (38\%), was to require the research team to complete the full ethics application. At these institutions this did not appear to be an intentional policy choice, but rather the result of systems that were not designed to review externally approved research in an efficient manner; where the application forms had not been created with a section to address externally approved research, the default process required external researchers to complete the whole application. The completed application did not necessarily go through the full review process, however. At 18 of those institutions there was a delegated review of the application form. However, while the time-to-approval was smooth, the process of completing 26 applications took five months and the dedicated time of three research assistants.

\section{Variation in Ethics Application Systems}

After the research team determined whether an ethics application was necessary, full or partial applications were submitted at the 45 institutions which required them. Throughout the application process, the variation in application forms and application systems became a subject of interest and, for the purposes of this article, all 69 submission systems and applications were examined for patterns, even where an application was not necessary. The first point of variation across institutions was the application system. The systems used by university REBs in Canada differ between those that accept applications via email and those that create an online account for researchers. In fall 2017, 29 of the 69 (40\%) university REBs were using an online account system to register proposed research projects and facilitate the ethics application process. The choice of online application servers differs among institutions as shown in Figure 1 below. Across Canada, the ROMEO platform is the most widely used, with IRISS or the francophone NAGANO also used at select institutions. ${ }^{1}$ In contrast, 10 institutions have online application systems linked to the academic research portal where faculty can manage their project funding and ethics in one account. In these cases, it is common for students to still use a Word Document or PDF form and submit their application by email since they are not eligible to access the faculty research portal. Within a year of this study (2017), two further universities launched online platforms and it is expected that more institutions will move in that direction in coming years.
For external researchers, application submission through ROMEO presents few barriers. The registration process can be accessed without directly contacting the REB and most institutions have set up their ROMEO template to accommodate expedited or delegated reviews for external researchers. Institutional research portals pose a somewhat greater challenge for an external researcher. In some cases, a campus identification number is needed and this often requires the researcher to liaise with the department of information services at the university. Other institutions require the external researcher to download a secure virtual network on their web browser each time they wish to access their application. This can be a tech-intensive process requiring multiple communications with either the REB or the institution's information technology support unit. Furthermore, external registration in these platforms occasionally expires, requiring the researcher to register again. While none of these limitations ultimately prevents ethical approval, encountering these small barriers at multiple institutions can lengthen the application-to-approval timeline significantly. In the case of our research project, we initially estimated that it would have taken approximately three months for our team of researchers, including valuable support from graduate students, to communicate with REBs and receive approval. Instead, the process took 10 months.

These complexities of the online application systems also pose an added level of difficulty for the ethics officers who are employed at the REBs. Troubleshooting the registration or technology details of the online accounts is beyond the scope of their own work portfolio and they must rely on their information technology supports to answer the queries of researchers. In our correspondence with ethics officers at dozens of institutions, it became clear that they are often the main face of the institutional REB for external and internal researchers alike and find themselves faced with the challenge of liaising between the researcher and the technology support team when they themselves have little control over the technology systems.

The technological requirements of REB application systems are not discussed in the TCPS2 (2018) document. The two places technology is addressed in TCPS2 includes Article 6.10, which suggests face-to-face or technology-assisted meetings for the Research Ethics Boards, and in the TCPS2 review documents which 


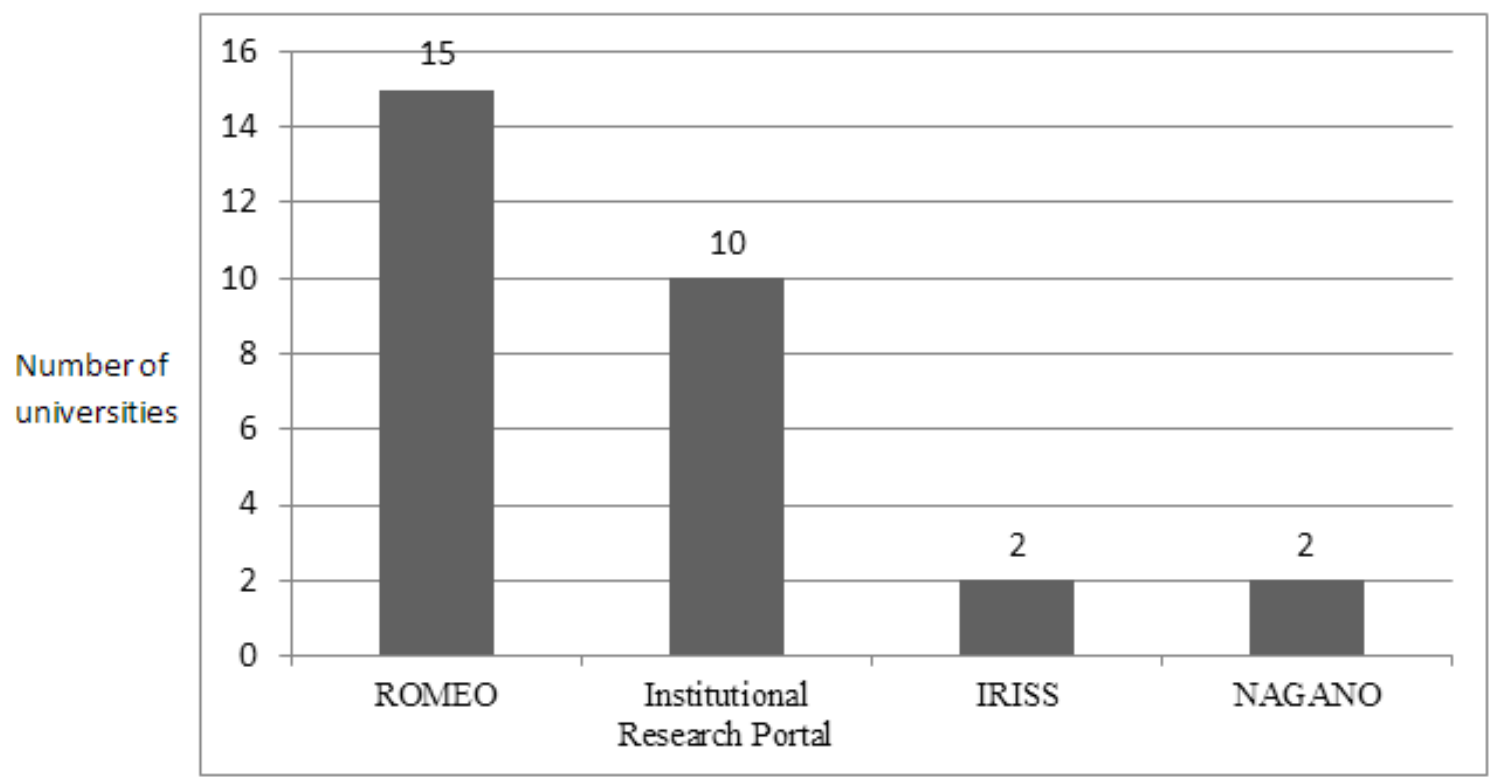

Name of online application platform

Figure 1. The number of REB's using online application platforms

outline the challenges of data storage in an era of technological advances (Pre-ethics, 2018). While the latter indicates researchers need to be wary of where their data is stored, there is little guidance indicating where the information provided in ethics applications should be stored or who should have access to it. Overall, for external researchers, application systems that do not require an online account or that have a delegated process for externally approved research provide the most efficient process for applying for ethics.

\section{Variation in Ethics Applications}

While the TCPS2 sets the standard for research ethics in Canada, there is still significant variation among the types of information REBs require from researchers on their application forms. The left column of Table 2 shows the common categories of information required at all institutions across Canada. In contrast, the right column lists the categories of information that are occasionally encountered at individual institutions.

While all institutions require researchers to provide the information listed in the left column of Table 2, it is surprising to note that the items in the right column are only required at certain institutions. In some cases, these items are closely linked to TCPS2 and the Tri-Council expectations and in others they are not (TCPS2, 2018). For example, only three institutions across Canada require external researchers to provide evidence that they have completed the online ethics tutorial offered by the Tri-Council on the subject of TCPS2. Likewise, TCPS2 (2018) mandates that "researchers shall demonstrate to their REBs that they have a reasonable understanding of the culture, values and beliefs of the population to be studied" (p. 22). Yet not all institutions ask researchers how they will address the specific cultural contexts of their participants. Alternatively, nine institutions do ask researchers to outline how they will address participants with limited literacy, since reading the consent form is a key step toward participant protection. Yet, nowhere in the TCPS2 document are varying levels of literacy noted as a key ethical concern. Ultimately, few of the institution-specific requirements in the right column are particularly arduous to fulfil since any valid research project should have on file items such as a literature review and citations. However, taken as a whole, they lengthen the approval timeline and highlight the lack of harmonization across Canadian REBs.

\section{Local Principal Investigators}

For external researchers, the variation in application sys- 
Table 2. Comparing the categories of data required on REB application forms

\begin{tabular}{|l|l|c|}
\hline Required on all institutions' REB forms & \multicolumn{2}{|l|}{ Required on some institutions' REB forms } \\
\hline Contact Information & & Number of Institutions \\
\hline Funding Agency & Citations used in research proposal & 2 \\
\hline Study Overview/Rationale & Cultural Considerations & 4 \\
\hline Methods & Dissemination of Findings & 15 \\
\hline Data Security & Indigenous Research & 6 \\
\hline Consent & Literacy of Participants & 4 \\
\hline Deception/Debriefing & Literature Review & 9 \\
\hline Benefits & Other REB Approvals & 15 \\
\hline Reimbursement & Secondary Data Analysis & 2 \\
\hline Conflict of Interest & TCPS2 Certificates & 3 \\
\hline Risk Level & Transcription Processes & 4 \\
\hline
\end{tabular}

tems and categories is a time-consuming exercise that delays data collection. A significantly greater barrier to approval exists at institutions where external researchers can only apply for ethics under the oversight of an internal principal investigator (PI). This requirement exists at three institutions and applies to studies that wish to use institutional resources to collect data. In the case of the APIKS survey, the institutional resource our study proposed to use was the university email system, with which a senior administrator would invite professors to complete the online survey. For this reason, a faculty or senior staff member from the university was required to approve the study and formally submit the study through their account in the online system on behalf of the research team. In the case of our study, this person was not provided automatically by the office that had agreed to send out the survey and several weeks were spent recruiting an internal collaborator. For external researchers, this requirement decreases the chances of successfully receiving study approval, particularly for those who lack a personal contact at the university. New relationships need to be formed to recruit an internal collaborator. Our correspondence with members at one of these institutions suggested that faculty were largely unaware of this requirement and were understandably hesitant to support a study with which they were unfamiliar.

The requirement of the local $\mathrm{PI}$ also raises signif- icant ethical questions for that individual; should a researcher take on administrative responsibility for a project of which they know little? In the case of ethical misbehaviour, is the internal researcher liable for the actions of the external researchers or responsible only for ensuring that the researchers are making ethical or appropriate use of institutional resources? In light of the fact that very few institutions across the country require an internal researcher and the challenge it poses for internal researchers, this requirement should be reassessed at institutions where it is practiced.

\section{Variation in Requested Revisions and the Ethical Implications of Ethics Revisions}

Despite the differences in ethics application systems and questions across the country, only 15 institutions required revisions to the protocol following the 45 reviews. All but one of these revisions addressed the language in the consent form and recruitment letter. The other required a survey appreciation page to conclude the survey. There were no requests to revise the survey tool itself, the recruitment processes or the sample population. The revisions to the consent form were implemented cumulatively, resulting in a very robust consent form being used for data collection by the end of the study. The most common request for revisions asked us to include 
the local REB's contact information on the informed consent page. The rationale for this requirement was that the institution itself was sending out the survey on our behalf and participating professors should be aware the study was approved by their own REB and have a link to that office if concerns should arise. However, it was only possible to fulfill this requirement by making custom versions of the online survey for each institution that wanted their REB contact information listed. This process resulted in 18 versions of the survey in both English and French.

The most complicating revision we encountered-at only one institution-was the requirement that we add their university's logo to our survey's informed consent page. While it is likely we were being asked to comply with the same standards as internal researchers who are affiliated with the university, this raised significant questions for us about the ownership of the survey and whether the logo might mislead participants as to the origins and authorship of the survey.

The above revisions-including contact information, new statements on the consent form and institutional logos-were required by a secondary REB on an application that had already received approval. These led to ethical concerns for our team about how many amendments we should make on the primary application at the home institution. Each time a university REB required a revision be made to the application at their institution, this altered the original protocol that had been approved by the University of Toronto. Was the research team responsible to file amendments at the University of Toronto noting every change requested by another institution? Furthermore, as an iterative process, ethics approval at one institution may have occurred months after the first round of applications were approved. Did we likewise have an obligation to report any later changes in the consent form to the REBs across Canada at which we were approved earlier? In the end, the research team submitted only four official amendments to our home institution's REB, but we had numerous conversations with the University of Toronto REB personnel to inform them of the ongoing complexity of our ethics applications across Canada.

\section{Discussion}

The findings of this review of ethics applications across
Canada indicate low levels of harmonization among institutional REBs when faced with an application that has been approved at a different institution. Despite the guiding principles of TCPS2, there is significant variation in the application systems, information requirements and expected revisions of university REBs in Canada. For both external researchers and the ethics officers that manage their applications, these discrepancies present extra work and lengthy delays in application approvals. In many cases, additional challenges are encountered in the technology of the application system or the requirement for an internal investigator-challenges which the researcher and the ethics officer are unable to resolve without third party involvement. The following section reflects on these findings and considers the strength of TCPS2 in facilitating harmonization and the broader conceptual approach to social science ethics in Canada.

\section{TCPS Chapters 6 and 8}

The variance in REB responses to the application of externally approved research is perhaps not surprising in light of responsibility and autonomy individual REBs are given in Chapter 6 of TCPS2, which states that "each institution is accountable for the research carried out in its own jurisdiction or under its auspices" (TCPS2, 2018, p. 1). Simply put, Chapter 6 makes institutions responsible for research taking place on their campuses and research conducted elsewhere by their researchers. Thus, institutions are responsible for reviewing research on their campus, whether it is conducted by those within their institution or those outside. It is interesting to note that this study found a discrepancy over what is considered on campus. While the majority of institutions considered the online survey of faculty used in the APIKS study to be on campus, two did not. Online surveys add to the complexity of what research is considered within an institution's jurisdiction. Data from the USA suggests REBs are unprepared to assess the ethical implications of online surveys related to data storage, sampling or survey design (Buchanan \& Hvizdak, 2009). Our research confirms that even the foundational principle of jurisdiction is called into question with online research tools.

Once institutions determine whether research is "within their jurisdiction or under their auspices," (TCPS2, 2018, p. 1) the decision of how to receive externally approved research has little oversight from TCPS2. 
At present, Chapter 8, in which multi-jurisdictional reviews are addressed, affords REBs significant autonomy. Chapter 8 suggests guidelines for REBs when they encounter "....a research project conducted by a researcher affiliated with one institution, but that involves collecting data or recruiting participants at different institutions" (TPCS2, 2018, p. 18). The introductory caveat of Chapter 8 places the responsibility on institutions when multi-jurisdictional research is undertaken. Chapter 8.1 states:

Where research involving humans requires the involvement of multiple institutions and/or multiple REBs, an institution may establish one or more, or a mix of models for research ethics review as described below. Institutions may also establish other models or arrangements that are appropriate for the research under review within their jurisdiction or under their auspices. The ultimate responsibility for approving alternative research ethics review models for potential use by REBs and researchers remains with their individual institutions. (TPCS2, 2018, p. 1)

According to this guideline, a number of arrangements between institutions can be made to accept reviews but if institutions should choose to implement another system that is in accordance with TCPS2, they are allowed.

Our study aligns with scholars who have argued the discrepancies in REB practices result from misinterpretations of the TPCS2 policy documents. Bakker (2006) contends that the specialized language of REB processes adds complexity rather than clarity to ethics reviews. Ells and Gutfreund (2006) present numerous quotes from the TPCS2 documents which are shown to be in conflict with REB practices. They recommend

...qualitative researchers and REBs refer to the text of the TCPS and interpret it in the context of specific research projects. We advise REBs to think beyond the medical model, and qualitative researchers to quote relevant passages from the TCPS in their protocol submissions to justify the procedures they propose. (pp. 361-362)

However, our findings suggest the increasing complexity and anonymity of the online REB systems stand as barriers to these suggestions, and only researchers with extensive time to engage in a dispute could challenge these issues.

\section{Consent and Ongoing Ethical Processes}

The opening quotation in this paper suggests that a deeper philosophical question is embedded in the discrepancies among REB protocols, asking, "What is the moral force of one policy against another? When studies are pursued across multiple jurisdictions, how should conflicting moral guidance be reconciled?" (Kimmelman et al., 2011, p. 7). Yet our study found the scrutiny on our application was focused solely on the nuances of the consent form, with no changes suggested for the data collection protocol. While a study which posed a greater risk to its participants may have experienced more intense scrutiny, ours did not. Thus, although the conceptual discussion on ethics considers questions of moral force or conflicting moral guidance, these questions may not be fully relevant to all ethics processes. Ethics officers have a large volume of complex work managing studies across their respective institutions and these philosophical debates appear detached from their work. Rather, the literature suggests REB processes are less concerned with the nature of research than they are with protecting researchers $₫$ and thus universities $\bigotimes$ through detailed consent forms (Christensen \& Prout, 2002; Powell \& Smith, 2006). Scholars argue that undue emphasis is put on consent without any monitoring of ongoing research. Ethics professionals might offer the caveat to the above observation that any research with a higher risk-factor would have been scrutinized more severely. However, if the low-risk nature does not demand in-depth scrutiny of the data collection methods themselves, perhaps that is also evidence to confirm that approval certificates and consent forms that have already been approved at a separate institution should be accepted more readily.

\section{Decentralized Ethics Reviews}

Higher education researchers who encounter difficulty acquiring ethics permission at multiple universities are prone to critique REB practices rather vocally. Yet the applications at each REB are reviewed by faculty members. These positions provide an opportunity for faculty to enter the REB space and contribute to the refinement of practice. Van den Hoonaard (2018) argues that the ethics process should be decentralized, allowing schol- 
ars to determine and regulate the ethics standards in their particular disciplines. Under this approach, social scientists within a particular field would both develop and regulate their own standards of ethical practice in a way that is tailored to protect their unique participants and advance their distinct methodologies. Van den Hoonaard (2018) refers to this process as allowing social scientists to own their own ethics since faculty are the ones who sit on REBs. This perspective is confirmed by Taylor and Patterson (2010), whose research on sociology departments highlights the distinct ways faculty understand ethics, and calls for more faculty consultation on protocols. Many REBs already have specialized review boards comprised of faculty from medical, animal and social science fields who review their own fields. Narrowing the scope of these boards would take this decentralization one step further, allowing for discipline-specific understanding of ethical research to guide scholarly inquiry.

\section{Provincial Coordination}

The nature of REB practices across Canada may be a mirror on the nature of governance of Canadian universities. Perhaps the fractious and highly decentralized (institution-to-institution and province-to-province) approach to ethics is simply reflective of the broader lack of a federal coordinating role in governing education in Canada. While the TCPS2 is a federal document, it is indicative of collaborative federalism. It hearkens to shared interests agreed upon collectively, but implemented locally. Thus, while harmonization efforts at the federal level may be a lofty goal, there is certainly room for provincial agreements along the lines of those in Alberta and British Columbia. Once strong provincial harmonization is in place, coordinating bodies from each province would be central agents able to share policies and practices with one another. Lastly, REBs are not the only departments attempting to coordinate inter-provincially. Our colleagues in professional disciplines have similar challenges with ensuring credential recognition between provinces-as teachers are very aware. Learning from other professions may be a helpful key to harmonizing REB practices across institutions and provinces.

\section{Areas for Further Research}

Numerous scholars across Canada have examined the disconnect between social science paradigms and REB practices. This growing body of research is an important step towards reshaping REBs to address the unique context of social science research. At the same time, there is significant room for more inter-institutional research on harmonization practices. Several areas for further research have emerged from this review of ethics processes. To what extent is REB practice explicitly linked to broader university goals? Is there evidence that particular types of institutions are more likely to experience ethics creep? What is the administrative location of REBs within the university and does this placing impact their scope? What are the main levels/determinants of ethics practice for a particular REB (i.e. TCPS2, provincial, global)? Answering these questions and others like them is an important step to understanding the national landscape of Canadian ethics and how institutions assess multi-jurisdictional social science research.

\section{Conclusion}

The findings of this article highlight the significant variation that exists in REB policy and practices across universities in Canada for multi-institutional research projects. The history of ethics policy development in Canada has left social scientists questioning whether their system is oriented too heavily toward the medical sciences. At the same time, the TCPS approach is a relatively new compliance model in Canada and institutions have significant autonomy, leading to ongoing adjustments and improvements in REB practices.

For researchers who embark on multi-jurisdictional projects, the differences in REB processes lengthen the application-to-approval timeline and increase the cost of conducting research. According to our calculations, the ethics review process for the APIKS study took three research assistants and the principal investigator a cumulative total of 550 hours and more than 25,000 dollars in grant money to complete. Luckily, we did not require annual renewals. Although our study did reach completion, increased harmonization might encourage more scholars to undertake pan-Canadian research on higher education.

This article offers several suggestions to aid the harmonization of REB processes across Canada, the most important being that REBs accept ethics certificates from other TCPS-compliant institutions. Furthermore, 
REBs would benefit from the development of standardized categories for applications and the establishment of decentralized ethics boards that tailor their reviews to specific disciplines. At a national level, those who consult on TCPS protocol might consider establishing guidelines to assist REBs in sharing best practices for implementing technology and systematic improvements related to REB applications. Ultimately, more national-level discussions are needed to clarify the different interpretations of TCPS2 guidelines. There is significant room for improvement in the harmonization among university REBs, both inter-provincially and federally. The harmonization agreements that have been developed in Alberta and British Columbia provide a helpful example for other provinces to consider. Furthermore, there is an increasing interest among scholars in examining and improving the REB practices in their institutions. The findings of this review as well as many of the studies referenced in this paper offer important suggestions for improving REB practices and increasing dialogue on ethical research practices across Canada.

\section{Acknowledgements}

The authors wish to thank Dr. Sandra Acker at the Ontario Institute for Studies in Education, University of Toronto, for her support and guidance during the development of this paper.

The authors acknowledge the financial support provided by the Ontario Human Capital Research and Innovation Fund (OHCRIF), administered by the Ontario Ministry of Training, Colleges and Universities, to develop this publication. The views expressed in this publication are the views of the authors and do not necessarily reflect those of the Government of Ontario.

The writing of this paper was supported by the Social Sciences and Humanities Research Council of Canada but the views expressed in this publication are the views of the authors and not SSHRC.

\section{References}

Bakker, J. I. (2006). Out of the clash of hermeneutic rules comes ethical decision making: But does it? Journal of Academic Ethics, 4(1-4), 11-38. https:/l doi-org.myaccess.library.utoronto.ca/10.1007/ $\underline{\text { s10805-006-9023-3 }}$
Buchanan, E. A., \& Hvizdak, E. E. (2009). Online survey tools: Ethical and methodological concerns of human research ethics committees. Journal of Empirical Research on Human Research Ethics, 4(2), 37-48. https://doi.org/10.1525/jer.2009.4.2.37

Chaiton, A., Paquet, G., and Wilson, C. (2000, March 15). Governance of the ethical process for research involving human subjects. Centre on Governance. Retrieved from http://www.christopherwilson.cal resources.html

Christensen, P., \& Prout, A. (2002). Working with ethical symmetry in social research with children. Childhood, 9(4), 477-497. https://doi. org/10.1177/0907568202009004007

Davies, M. (2008). Raising the bar: Ethics review, governance, and accountability in community-based human health research. Saskatchewan Law Review, 71, 91-116. https://sasklawreview.cal

Ells, C., \& Gutfreund, S. (2006). Myths about qualitative research and the Tri-Council policy statement. The Canadian Journal of Sociology/Cahiers canadiens de sociologie, 31(3), 361-373. https://doi. org/10.2307/20058715

Grover, S. (2004). What's human rights got to do with it? On the proposed changes to SSHRC ethics research policy. Journal of Academic Ethics, 2(3), 249-262. https://doi.org/10.1007/s10805-004-5003-7

Guta, A., Nixon, S. A., \& Wilson, M. G. (2013). Resisting the seduction of "ethics creep": Using Foucault to surface complexity and contradiction in research ethics review. Social Science and Medicine, 98, 301-310. https://doi.org/10.1016/j. socscimed.2012.09.019

Haggerty, K. D. (2004). Ethics creep: Governing social science research in the name of ethics. Qualitative sociology, 27(4), 391-414. https://doi.org/10.1023/ B:QUAS.0000049239.15922.a3

Kimmelman, J., McDonald, M., \& Avard, D. (2011). A guide to the perplexed: How to navigate conflicting research ethics policies. Health Law Review, 19(3), 56-62. https://www.ualberta.ca/health-law-institute/ journals/healthlawreviewarchive

McDonald, M. (2009). From code to policy statement: 
Creating Canadian policy for ethical research involving humans. Health Law Review, 17(2/3), 12-25. https://www.ualberta.ca/health-law-institute/ journals/healthlawreviewarchive

Morrow, V., \& Richards, M. (1996). The ethics of social research with children: An overview. Children \& Society, 10(2), 90-105. https://doi. org/10.1111/j.1099-0860.1996.tb00461.x

Palys, T. S. (1996). The ethics of ethics: Comments regarding the Tri-Council working group's March 1996 Draft code of conduct for research involving humans. Retrieved from http://www.sfu.ca/ palys/ codecomm.htm

Porter, T. (2008). Research ethics governance and political science in Canada. PS: Political Science \& Politics, 41(3), 495-499. https://doi.org/10.1017/ S1049096508080852

Powell, M. A., \& Smith, A. B. (2006). Ethical guidelines for research with children: A review of current research ethics documentation in New Zealand. Kotuitui: New Zealand Journal of Social Sciences Online, 1(2), 125-138. https://doi.org/10.1080/11770 83X.2006.9522415

Pre-ethics. (2018). Review of Chapter 5: Tri-Council Policy Statement 2018. Retrieved from https://ethics.gc.ca/eng/tcps2-eptc2 2018 chapter5-chapitre5. $\underline{\mathrm{html}}$

TCPS2. (2018). Multi-jurisdictional Research. Tri-Council Policy Statement, Chapter 8. Retrieved from https://ethics.gc.ca/eng/tcps2-eptc2 chapter8-chapitre8.html

Taylor, J., \& Patterson, M. (2010). Autonomy and compliance: How qualitative sociologists respond to institutional ethical oversight. Qualitative Sociology 33(2), 161-183. https://doi.org/10.1007/s11133-0109148-y

Tierney, W. G., \& Blumberg Corwin, Z. (2007). The tensions between academic freedom and institutional review boards. Qualitative Inquiry, 13(3), 388-398. https://doi.org/10.1177/1077800406297655

Tilley, S. A. (2008). A troubled dance: Doing the work of research ethics review. Journal of Academic Ethics, 6(2), 91-104. https://doi.org/10.1007/s10805-008- $\underline{9058-8}$

Van den Hoonaard, W. C. (2011). The seduction of ethics: Transforming the social sciences. Toronto, ON: University of Toronto Press.

Van den Hoonaard, W. C. (2018). Autobiographical notes from inside the ethics regime: Some thoughts on how researchers in the social sciences can own ethics. Forum Qualitative Sozialforschung/Forum: Qualitative Social Research, 19(3), 1-20. https://doi. org/10.17169/fqs-19.3.3024

\section{Contact Information}

Grace Karram Stephenson

grace.karram@utoronto.ca

\section{Notes}

1 ROMEO, IRISS and NAGANO are web-based application forms used by universities across Canada to administer their ethics protocols. Within each application, institutions have the ability to select or create specific questions to ask on their ethics application forms. Therefore, two institutions may use ROMEO but the application form questions will differ. 